\title{
Bisfosfonatos:
}

\section{Os Compostos Multivalentes da Indústria Farmacêutica}

\begin{abstract}
Bisphosphonates: the multivalent compounds of the pharmaceutical industry. Bisphosphonates (BPOs) are a class of compounds of growing interest to the pharmaceutical industry. Offering the readership the chance to improve the knowledge on these compounds, this article begins by describing the circumstances of their discovery, followed by a description of their composition, structure and the mechanisms underlying their therapeutic effects. The description of their clinical uses is presented under two main categories, one concerning their use as regulators of bone metabolism, and the other as therapeutic agents for malignant bone disorders. Further highlight is given to new applications of BPOs developed over the last few years, ranging from imagiology to potential biological applications of their chelating abilities. The last section presents a comprehensive overview on the synthetic procedures available to prepare BPOs. The limitations of the current methods are described, and emerging improved methodologies are presented. In the near future, these innovative methods are expected to provide an adequate response to the growing demand of BPOs.
\end{abstract}

Os bisfosfonatos (BPOs) são uma classe de compostos com grande interesse farmacêutico. Para oferecer ao leitor a possibilidade de conhecer melhor estes compostos, começa-se por apresentar uma breve descrição das circunstâncias que rodearam a sua descoberta, apresentando-se de seguida a sua composição, estrutura e os mecanismos pelos quais exercem a sua ação terapêutica. As indicações terapêuticas dos BPOs são apresentadas em duas categorias, uma referente ao seu uso mais comum como reguladores do metabolismo ósseo, e a segunda reportando-se ao uso em lesões ósseas associadas a neoplasias. Destacam-se ainda novas aplicações que nos últimos anos têm vindo a ser desenvolvidas para os BPOs, em áreas que vão desde a imagiologia a potenciais aplicações biológicas da sua ação quelante de metais. Para finalizar, é apresentada uma análise detalhada das diferentes variantes de sintese dos BPOs. Ilustram-se as limitações dos métodos atuais bem como os novos e mais eficazes métodos de preparação propostos por diferentes investigadores que se prevê permitirem, num futuro próximo, responder adequadamente ao aumento da procura de BPOs.

\section{Perspetiva histórica: foram os bisfosfonatos na farmácia um fruto do acaso? Os bisfosfonatos (BPOs) foram descobertos pela primeira vez em 1894 pelo farmacêutico Theodor Salzer, sendo inicialmente utilizados em processos industriais como inibidores de corrosão ou agentes complexantes nas indústrias têxtil, de fertilizantes e do petróleo [1,2]. Somente sete décadas depois, em 1962, é que o seu potencial biológico e terapêutico foi descoberto por Herbert Fleisch, no decurso de estudos para avaliar mecanismos de calcificação com pirofosfato inorgânico (PPi). Nestes, observou que o PPi, normalmente presente nos fluidos corporais, tem a capacidade de se ligar à hidroxiapatite (HAP, fosfato de cálcio que constitui o}

tecido ósseo) e de evitar a sua dissolução, prevenindo desta forma a calcificação de tecidos moles. Com base nestes resultados, e dado que o PPi é um composto análogo aos BPOs (Figura 1), foram realizados estudos adicionais para avaliar se os BPOs teriam um efeito semelhante. De facto, foi demonstrado que, tal como o PPi, os BPOs também são capazes de inibir a calcificação de tecidos moles. Mais importante ainda foi a observação concomitante de que os BPOs evitam a destruição de tecido ósseo [3,4]. É sobre esta última característica que têm recaído as mais recentes aplicações dos BPOs na indústria farmacêutica. 
$(\mathrm{HO})_{2} \mathrm{OP}-\mathrm{O}-\mathrm{PO}(\mathrm{OH})_{2}$

Pirofosfato Inorgânico<smiles>[R]C([R2])([PoH]O)[Po]([O-])O</smiles>

Ácido Bisfosfónico genérico

\section{A importância da estrutura dos BPOs na sua função terapêutica}

A estrutura molecular dos BPOs (Figuras 1 e 2) consiste em dois grupos fosfonato ligados a um átomo de carbono central por ligacções fosfo-éter não hidrolisáveis (grupo central P-C-P), e em duas cadeias laterais $R_{1}$ e $R_{2}$ ligadas covalentemente ao carbono central. A cadeia lateral $R_{2}$ é específica para cada BPO [5].

A atividade terapêutica dos BPOs está dependente do grupo central P-C-P que confere afinidade para o tecido mineral ósseo (hidroxiapatite), mas é também definida pelas cadeias laterais $R_{1}$ e $R_{2}$. Modificações em um dos grupos fosfonato (ou em ambos) como, por exemplo, a substituição de um grupo hidroxilo por um grupo metilo, resultam numa diminuição da afinidade para o tecido ósseo, comprometendo, consequentemente, a eficiência terapêutica [2,6-8]. A cadeia $R_{1}$ também contribui para criar afinidade para o tecido ósseo, no caso de ser apenas constituída por um grupo $\mathrm{OH}$. O hidroxilo cria um local adicional de coordenação aos iões cálcio presentes na hidroxiapatite (HAP), formando-se uma ligação tridentada em vez de uma bidentada. Por seu turno, a cadeia $R_{2}$ é responsável pelo potencial terapêutico específico de cada BPO, sendo que a presença (ou não) de grupos com átomos de nitrogénio $(\mathrm{N})$ pode traduzir-se em diferentes afinidades de ligáção e influenciar a extensão da adsorção e retenção dos BPOs $[5,6,9,10]$.

Os BPOs, após a adsorção ao osso, ficam em contacto com as células deste tecido, podendo interferir com o seu normal funcionamento, nomeadamente com o processo de remodelação óssea'. Está demonstrado que os BPOs adsorvidos à superfície óssea são internalizados pelos osteoclastos, células responsáveis pela degradação óssea durante o processo de remodelação [5,7]. Uma vez no meio intracelular dos osteoclastos, os BPOs exercem um efeito catalítico que segue diferentes mecanismos de ação de acordo com a presença ou ausência de átomos de nitrogénio no grupo $\mathrm{R}_{2}$ ( $\mathrm{N}$-BPOs ou não-N-BPOs) (Figuras 2 e 3) $[5,6,9,10]$. Os não-N-BPOs (sais de etidronato e clodronato) são metabolizados intracelularmente em conjunto com o monofosfato de adenosina (AMP) e originam análogos de ATP não hidrolisáveis e tóxicos. Os $\mathrm{N}$-BPOs (sais de pamidronato, alendronato, ibandronato, risedronato e zoledronato), além de originarem análogos de ATP tóxicos, inibem igualmente enzimas responsáveis pela síntese de metabolitos-chave para os osteoclastos. 0 resultado desta ação dos BPOs é a apoptose dos osteoclastos e a diminuição da destruição do osso que por eles seria feita $[2,5,7,11-16]$. Note-se que a atividade anti-osteoclástica permanece como o foco principal da ampla aplicação dos BPOs na terapêutica.

\section{Não-N-BPOs}

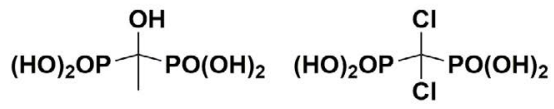

Ácido Etidrónico Ácido Clodrónico

N-BPOs

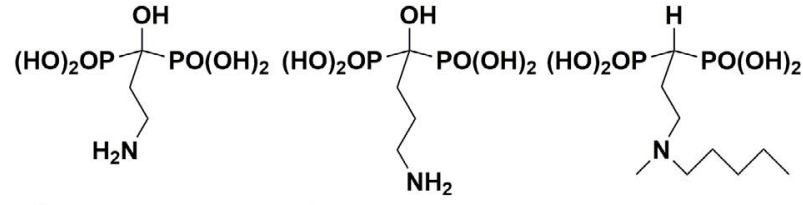

Ácido Pamidrónico Ácido Alendrónico Ácido Ibandrónico

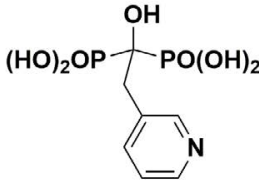

Ácido Risedrónico

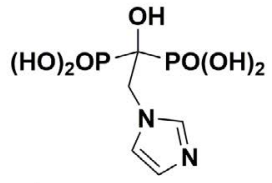

Ácido Zoledrónico
Figura 2 - Estrutura molecular dos ácidos bisfosfónicos disponiveis comercialmente. 
Figura 3 - Esquema ilustrativo demonstrando: (a) a internalização dos BPOs pelos osteoclastos; e (b) os mecanismos de ação pelos quais os BPOs provocam a apoptose dos osteoclastos. Adaptada das referências $[5,12]$.

a) Internalização dos BPOs pelos osteoclastos

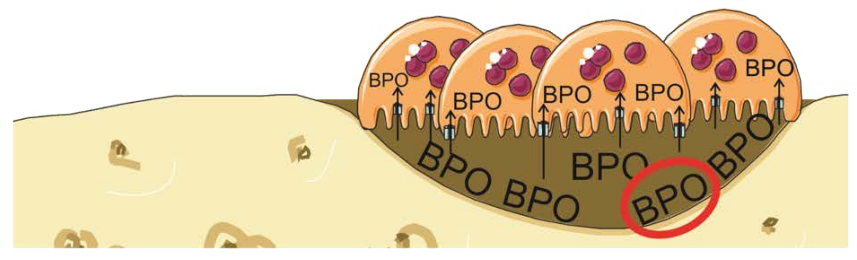

b) Mecanismos de ação dos BPOs nos osteoclastos

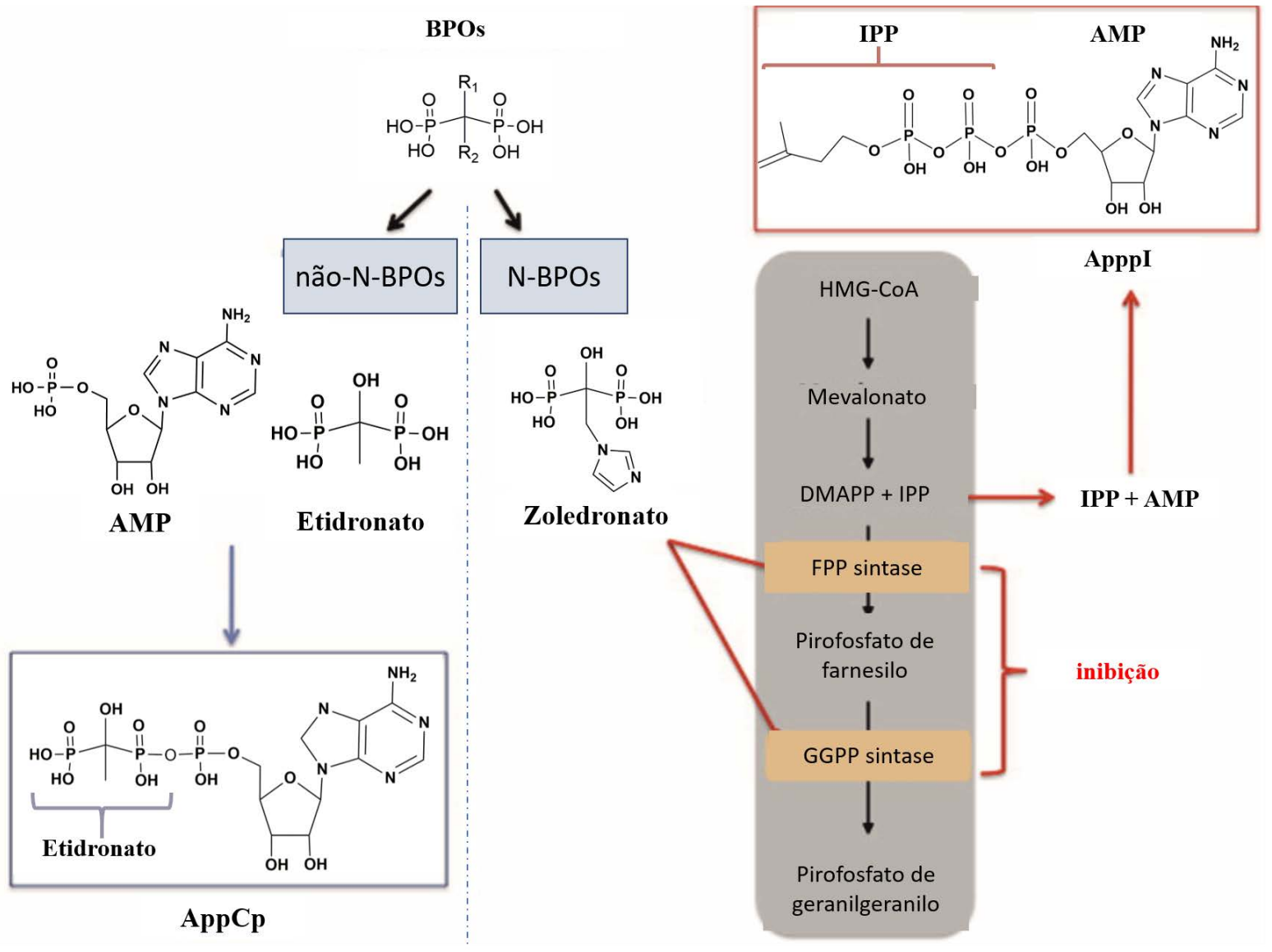

\section{Aplicações dos BPOs}

Atualmente, as aplicações terapêuticas dos BPOs estão centradas na sua capacidade de interferir com o processo de remodelação do tecido ósseo por ação anti-osteoclástica e diminuição da perda de tecido ósseo. Os BPOs são amplamente usados como agentes terapêuticos em inúmeras formulações farmacêuticas para patologias em que ocorre uma elevada destruição óssea $[7,17]$.

\subsection{Tratamento da osteoporose: o uso} mais comum

O uso terapêutico mais comum dos BPOs é no tratamento da osteoporose, uma disfunção que está associada ao aumento exacerbado da atividade dos osteoclastos e, consequentemente, a uma elevada degradação do tecido ósseo $[18,19]$. A osteoporose surge normalmente associada ao envelhecimento dos indivíduos e, nas mu- 
Iheres, pode ser potenciada pelas alterações hormonais resultantes da menopausa. Caracteriza-se por perda progressiva da densidade óssea, acompanhada pela perda da arquitetura estrutural e resistência mecânica dos ossos (Figura 4). Existe, portanto, um maior risco de fraturas que, consequentemente, promove limitações no estilo de vida dos pacientes. Contudo, as implicações mais severas estão associadas a casos em que ocorre efetivamente uma fratura, havendo frequentemente uma recuperação mais demorada e taxas mais elevadas de morbilidade e mortalidade [11,18,20,21].

A osteoporose afetava já em 2012 uma parte significativa da população portuguesa - cerca de meio milhão de pessoas. A maior prevalência em idosos é um fator preocupante quando se considera o atual aumento da esperança média de vida, isto porque permite estimar que o número de pacientes osteoporóticos continuará a aumentar gradualmente $[20,22,23]$. Tendo em conta todos estes aspetos, não é surpreendente que se encontrem várias formulações à base de BPOs disponíveis no mercado farmacêutico para o tratamento da osteoporose (medicamentos genéricos ou de marca, Tabela 1) [7,8,24-28].
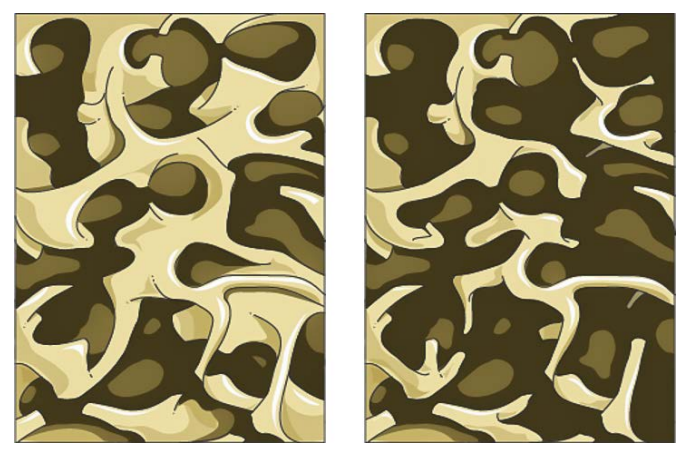

Figura 4 - Representação ilustrativa da morfologia de um osso saudável (esquerda) e osteoporótico (direita).

A eficácia dos BPOs como fármacos no tratamento da osteoporose é corroborada por diversos estudos. Um estudo longitudinal com mulheres na pós-menopausa sob administração continuada de alendronato por um período de 10 anos mostrou um aumento significativo da densidade mineral óssea, em cerca de 10 a $13 \%$ na coluna vertebral e 5 a $6 \%$ no osso femoral. 0 estudo demonstrou ainda que este efeito se associa à diminuição da degradação óssea, medida por marcadores na urina, nomeadamente resíduos de colagénio (um dos principais componentes do osso). As pacientes continuaram a ser observadas por um ano após a descontinuação, tendo-se registado, ao fim desse ano, uma ligeira redução do efeito terapêutico, embora sem reverter aos valores antecedentes ao tratamento [30]. Num outro estudo, a administração de
Tabela 1 - Exemplos de formulações de BPOs (e dos seus sais) disponíveis no mercado Português [29].

\begin{tabular}{|c|c|c|}
\hline Nome Comercial & Formulação & Fabricante \\
\hline \multicolumn{3}{|c|}{ Ácido Alendrónico e Alendronato de Sódio } \\
\hline Fosamax & Comprimido & Merck Sharp \& Dohme, Lda. \\
\hline Bonasol & $\begin{array}{l}\text { Solução Líquida } \\
\text { Oral }\end{array}$ & $\begin{array}{c}\text { Laboratórios Azevedos - Indústria } \\
\text { Farmacêutica, S.A. }\end{array}$ \\
\hline Binosto & $\begin{array}{l}\text { Comprimido } \\
\text { Efervescente }\end{array}$ & Laboratórios Atral, S.A. \\
\hline Ácido Alendrónico GP & $\begin{array}{l}\text { Comprimido } \\
\text { Revestido }\end{array}$ & GP - Genéricos Portugueses, Lda. \\
\hline Ácido Alendrónico Jaba & $\begin{array}{l}\text { Comprimido } \\
\text { Revestido }\end{array}$ & Jaba Recordati, S.A. \\
\hline Ácido Alendrónico Azevedos & Comprimido & $\begin{array}{c}\text { Laboratórios Azevedos - Indústria } \\
\text { Farmacêutica, S.A. }\end{array}$ \\
\hline \multicolumn{3}{|c|}{ Ácido Ibandrónico } \\
\hline $\begin{array}{l}\text { Ácido Ibandrónico } \\
\text { Aurobindo }\end{array}$ & $\begin{array}{c}\text { Comprimido } \\
\text { Revestido }\end{array}$ & Generis Farmacêutica, S.A. \\
\hline Ácido Ibandrónico Bluefish & $\begin{array}{l}\text { Comprimido } \\
\text { Revestido }\end{array}$ & Bluefish Pharmaceuticals AB \\
\hline Ácido Ibandrónico Stada & $\begin{array}{l}\text { Comprimido } \\
\text { Revestido }\end{array}$ & Stada, Lda. \\
\hline \multicolumn{3}{|c|}{ Risedronato de Sódio } \\
\hline Actonel & $\begin{array}{l}\text { Comprimido } \\
\text { Revestido }\end{array}$ & Theramex Ireland Limited \\
\hline Risedronato de sódio Mylan & $\begin{array}{l}\text { Comprimido } \\
\text { Revestido }\end{array}$ & Mylan, Lda. \\
\hline Risedronato de sódio Ciclum & $\begin{array}{c}\text { Comprimido } \\
\text { Revestido }\end{array}$ & Ciclum Farma Unipessoal, Lda. \\
\hline Risedronato de sódio Teva & $\begin{array}{c}\text { Comprimido } \\
\text { Revestido }\end{array}$ & Accord Healthcare, S.L.U. \\
\hline \multicolumn{3}{|c|}{ Ácido Zoledrónico } \\
\hline Aclasta & $\begin{array}{c}\text { Solução para } \\
\text { perfusão }\end{array}$ & Novartis Europharm, Ltd. \\
\hline
\end{tabular}

ibandronato a mulheres osteoporóticas ao longo de um ano apresentou resultados semelhantes. Observou-se uma diminuição de degradação óssea, medida pelos níveis urinários de resíduos de colagénio, bem como um aumento da densidade óssea [31]. 0 risedronato e o ácido zoledrónico, em estudos com a duração de três e um anos, respetivamente, induziram um aumento na densidade óssea dos pacientes, permitindo reduzir significativamente o número de fraturas ósseas em pacientes com osteoporose [32,33].

No seu conjunto, os estudos apresentados demonstram que a administração de BPOs é benéfica para os pacientes osteoporóticos. Os BPOs permitem diminuir a degradação do tecido ósseo, levando a um ligeiro aumento de densidade óssea e diminuindo o número de fracturas a que os pacientes estão sujeitos.

\subsection{Tratamento de outras patologias: a sua potencialidade em quadros neoplásicos}

Nos EUA, os BPOs recebem a categoria terapêutica de "agentes para doenças metabólicas do tecido ósseo", o que reflete uma gama de patologias enumerada na Tabela 2 [34]. Para além da prevenção e tratamento da osteoporose [35,36], surgem na prevenção e tratamento de lesões osteolíticas associadas a quadros 
Tabela 2 - Exemplos de formulações de BPOs (e dos seus sais) disponíveis nos EUA e respetivas indicações terapêuticas [17].

\begin{tabular}{|c|c|c|}
\hline Nome Comercial & Formulação & Uso Terapêutico \\
\hline \multicolumn{3}{|c|}{ Pamidronato de Sódio } \\
\hline Aredia & Solução para Injeção Intravenosa & $\begin{array}{c}\text { Hipercalcemia associada a malignidade, metástases ósseas osteolíticas do cancro } \\
\text { da mama, lesões osteolíticas do mieloma múltiplo, doença de Paget }\end{array}$ \\
\hline \multicolumn{3}{|c|}{ Alendronato de Sódio } \\
\hline Fosamax & Comprimido & Osteoporose, doença de Paget \\
\hline Binosto & Comprimido Efervescente & Osteoporose \\
\hline \multicolumn{3}{|c|}{ Ibandronato de Sódio } \\
\hline Boniva & Comprimido & Osteoporose \\
\hline Boniva & Solução para Injeção Intravenosa & Osteoporose \\
\hline Ibandronate Sodium & Solução para Injeção Intravenosa & Osteoporose \\
\hline \multicolumn{3}{|c|}{ Risedronato de Sódio } \\
\hline Actonel & Comprimido & Osteoporose, doença de Paget \\
\hline Atelvia & Comprimido de Libertação Controlada & Osteoporose \\
\hline Risedronate Sodium & Comprimido & Osteoporose, doença de Paget \\
\hline \multicolumn{3}{|c|}{ Ácido Zoledrónico } \\
\hline Reclast & Solução para Injeção Intravenosa & Osteoporose, doença de Paget \\
\hline Zometa & Solução para Injeção Intravenosa & Hipercalcemia associada a malignidade, mieloma múltiplo, metásteses ósseas \\
\hline Zoledronic Acid & Solução para Injeção Intravenosa & Hipercalcemia associada a malignidade, mieloma múltiplo, metásteses ósseas \\
\hline
\end{tabular}

de mieloma [37] e de metástases ósseas associadas a cancro da mama [38]. Na Europa, os BPOs começaram, no início dos anos 90, por ser usados no tratamento de casos de hipercalcemia (níveis excessivamente elevados de cálcio no sangue) e na prevenção de alterações no tecido ósseo em pacientes com cancro. Anos mais tarde, em meados dos anos 90, o seu uso ampliou-se a casos de osteoporose e à doença de Paget (patologia derivada da exacerbada atividade dos osteoblastos e osteoclastos - ver nota 1 - em algumas zonas do osso, zonas essas cuja área aumenta significativamente, mas apresenta tecido ósseo frágil e estruturalmente anormal) [20,39,40].

\section{O que esperar dos bisfosfonatos no futuro?}

Além de serem globalmente utilizados como princípio terapêutico no tratamento de diversas patologias do osso, os BPOs têm sido também o foco de vários estudos com o intuito de melhorar as formulações já conhecidas, assim como ampliar a gama de aplicações [41-44].

\subsection{Novas formulações: menos efeitos secundários e maior biodisponibilidade?}

Não obstante aos efeitos terapêuticos dos BPOs, e após os vários anos de utilização desta classe de compostos, tornou-se evidente a correlação entre o seu uso e o aparecimento de efeitos colaterais indesejados. Normalmente, estes compreendem sintomas gastrointestinais, como a irritação do esófago ou da mucosa gástrica $[45,46]$. Estudos mais recentes têm correlacionado a administração de BPOs a um maior risco de desenvolver cancro do esófago [47], ou ao aparecimento de osteonecrose da mandíbula $[48,49]$. Aquando da injeção intravenosa de determinados BPOs, têm surgido casos de toxicidade renal, por vezes graves, devido aos elevados níveis séricos de BPOs que são posteriormente eliminados por via renal [50].

Os BPOs disponíveis comercialmente apresentam outra grande limitação à sua eficácia terapêutica: a sua baixa biodisponibilidade. Na sua maioria, as formulações de BPOs são administradas por via oral, tendo, portanto, de ser absorvidos no trato gastrointestinal (GI) para atingir a circulação sistémica, sendo só depois distribuídos até chegarem ao local de ação, o tecido ósseo. No entanto, dado que os BPOs são compostos extremamente hidrofílicos, a sua absorção através das células epiteliais do trato GI não é possível pois não atravessam a membrana celular. Em alternativa, são absorvidos através das junções entre estas células (tight junctions), o que causa a sua baixa biodisponibilidade. Apenas uma pequena fração dos BPOs presentes na formulação comercial atinge de facto a circulação sistémica, 
podendo depois atuar no tecido ósseo [51,52]. De acordo com estudos na literatura, a administração oral dos BPOs pamidronato, alendronato, ibandronato e risedronato está associada a valores de biodisponibilidade compreendidos entre 0,31-0,48 [53], 0,59-0,76 [54], 0,44-0,6 [55,56] e 0,6-0,63\% $[57,58]$, respetivamente. Esses valores tendem a ser ainda mais baixos quando a administração do BPO ocorre aquando da ingestão de alimentos, o que implica a toma dos BPOs em jejum e, pelo menos, trinta minutos antes da primeira refeição do dia. Por sua vez, no caso em que os BPOs são administrados por via intravenosa, como por exemplo os ácidos pamidrónico e zoledrónico, toda a quantidade de BPO administrada estará disponível na circulação sistémica, para ser posteriormente distribuída pelo local de ação. No entanto, foi demonstrado que ca. $46 \pm 16 \%$ e $39 \pm 16 \%$ das doses do ácido pamidrónico e zoledrónico administrados são excretadas na urina. Ou seja, mesmo através de injeção intravenosa, apenas pouco mais de metade da dose de BPO administrada chega efetivamente ao tecido ósseo [59-62].

Em busca de terapias capazes de manter a ação benéfica dos BPOs, enquanto se tentam evitar os efeitos colaterais e melhorar a sua biodisponibilidade, diferentes grupos de investigação têm procurado vias de administração alternativas e formulações inovadoras. Este processo passa, por vezes, pelo desenvolvimento de formulações de BPOs que possam ser aplicadas diretamente no tecido ósseo, no decurso de uma intervenção cirúrgica [63]. Tal é o caso de, por exemplo, cimentos ósseos contendo na sua composição BPOs como o alendronato ou pamidronato $[64,65]$. Em alternativa, têm sido desenvolvidos sistemas de entrega menos invasivos, e, portanto, mais bem aceites pelo doente. Estes baseiam-se em géis ou cimentos injetáveis que permitem a libertação dos BPOs nas zonas alvo $[66,67]$. Nesta área, os cimentos ósseos injetáveis à base de fosfato de cálcio (CaP) parecem ser particularmente promissores para a entrega local de BPOs. Além de serem biocompatíveis, bioativos e osteogenéticos, existe uma elevada afinidade dos BPOs em relação ao cálcio, presente em grande quantidade nestes cimentos [68]. Uma outra abordagem passa pelo desenvolvimento de novas formulações orais [69]. Estas podem compreender formulações à base de nano-lipossomas que são absorvidas com grande eficácia (e podem evitar parte da eliminação renal), ou ainda a preparação de comprimidos revestidos ou cápsulas de gelatina, compostos por uma mistura física do BPO e dois excipientes, um que permita melhorar a absorção intestinal do BPO (dodecilssulfato de sódio), e outro que atue como agente quelante de cálcio, limitando a complexação do BPO com este ião e consequente precipitação (myo-inositol-hexakis(dihydrogenphosphatedodecasodium salt) $[70,71]$. Note-se, contudo, que a maioria destes estudos ainda estão em estágios iniciais de desenvolvimento, com exceção do último exemplo que já se encontra patenteado. Desta forma, o processo até à sua comercialização, se alcançada, pode ser longo.

\subsection{Novas aplicações farmacológicas}

A ação anti-osteoclástica dos BPOs torna-os potencialmente úteis no tratamento de periodontite, uma doença inflamatória do periodonto, de origem predominantemente bacteriana. Além da gengiva, o periodonto compreende toda a estrutura fisiológica que fixa os dentes na cavidade bucal, incluindo ligamentos e tecido ósseo. A periodontite caracteriza-se por uma perda progressiva do osso à volta do dente, que fica progressivamente mais solto e pode, eventualmente, cair. Um estudo piloto recorreu a alendronato, formulado em gel, para preencher as cavidades da zona periodontal de cinco pacientes. Seis meses após o tratamento, foi observada uma diminuição significativa da degradação de tecido ósseo, sendo também visível o aumento da formação de osso na área de análise (círculo vermelho demarcado na Figura 5) [67].

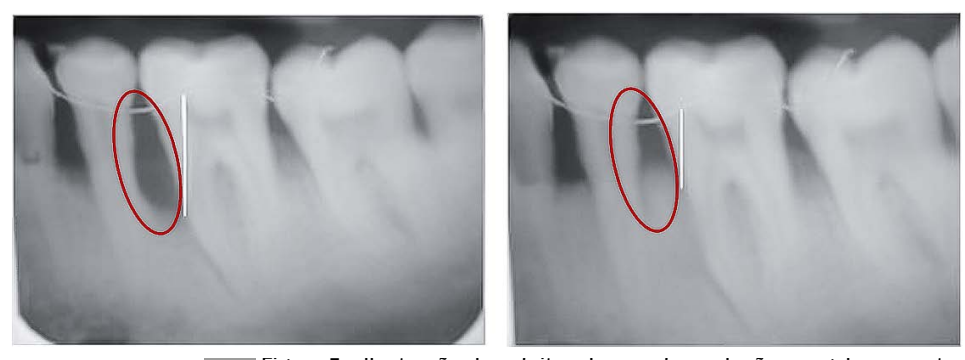

rıgura 5 - Ilustraçäo dos eteitos de uma tormulaçāo em gel composta pelo BPO alendronato num doente com periodontite, no início (esquerda) e após seis meses da aplicação (direita). Adaptada da referência [67].

Numa perspetiva diferente, ao invés de serem usados como fármacos, os BPOs podem ser usados como agentes para a entrega de outros princípios ativos ao tecido ósseo [72,73]. Um exemplo é o anti-inflamatório Diclofenac, vulgarmente utilizado no tratamento do reumatismo articular crónico, mas cuja repetida e frequente administração pode acarretar problemas gastrointestinais. Para evitar tais efeitos, e tirando partido da seletividade dos BPOs para o tecido ósseo, Hata et al. prepararam 
bioconjugados de BPO-Diclofenac. Desta forma, - BPO atua como uma sonda para transportar o Diclofenac em maior quantidade para o osso, permitindo reduzir o número de administrações deste fármaco. A conjugação ao BPO também ajuda a evitar a distribuição do Diclofenac por outros tecidos, onde exerceria efeitos secundários [74].

Num outro estudo, Rudnick-Glick et al. prepararam nanopartículas funcionalizadas à superfície com BPOs e Doxorrubicina. Este último é um fármaco amplamente utilizado na quimioterapia para o tratamento de cancro, como por exemplo o osteossarcoma, mas cuja administração envolve doses bastante elevadas estando, portanto, associada a efeitos secundários indesejáveis. As nanopartículas visam contornar as limitações do fármaco através da ação dos BPOs presentes na sua superfície que as guia especificamente para o tecido ósseo. Estudos in vivo, num modelo de embrião de galinha com um xenoenxerto de osteossarcoma humano Saos-2, demonstraram que estas nanopartículas são significativamente mais eficazes do que a Doxorrubicina pura na inibição do crescimento tumoral [75].

\subsection{BPOs como novos agentes \\ imagiológicos}

Os BPOs têm demonstrado também a sua utilidade na área da imagiologia. Dado a sua elevada afinidade para o tecido ósseo, estes compostos podem ser usados para a preparação de conjugados capazes de complexar isótopos como o ${ }^{68} \mathrm{Ga}$ ou o ${ }^{99 \mathrm{~m} T c}$, podendo, no final, ser usados como agentes de contraste do osso. Este tipo de conjugados apresenta ainda uma capacidade de diagnóstico, pois, além de marcarem todo o esqueleto, são acumulados com mais expressão em áreas de elevada taxa de remodelação óssea, como por exemplo metástases ósseas ou microcalcificações resultantes de cancro (Figura 6) [76-78]. A nível laboratorial, esta atividade também pode ser útil, conforme mostrou a equipa de Sun et al. ao preparar uma série de BPOs (risedronato, zoledronato ou análogos) conjugados com grupos emissores de fluorescência - fluoróforos (por exemplo, 6-carboxifluoresceína, 6-FAM, ou Rhodamine Red $^{\text {TM }}-\mathrm{X}$, RhR-X) que vão distribuir-se de forma específica e localizada no tecido ósseo e marcá-lo com a fluorescência característica de cada fluoróforo. Os autores esperam que a vasta gama de conjugados preparados possa, graças às suas propriedades espectroscópicas distintas, ser aplicada em estudos imagiológicos para melhor compreender a fisiologia do tecido ósseo [79].

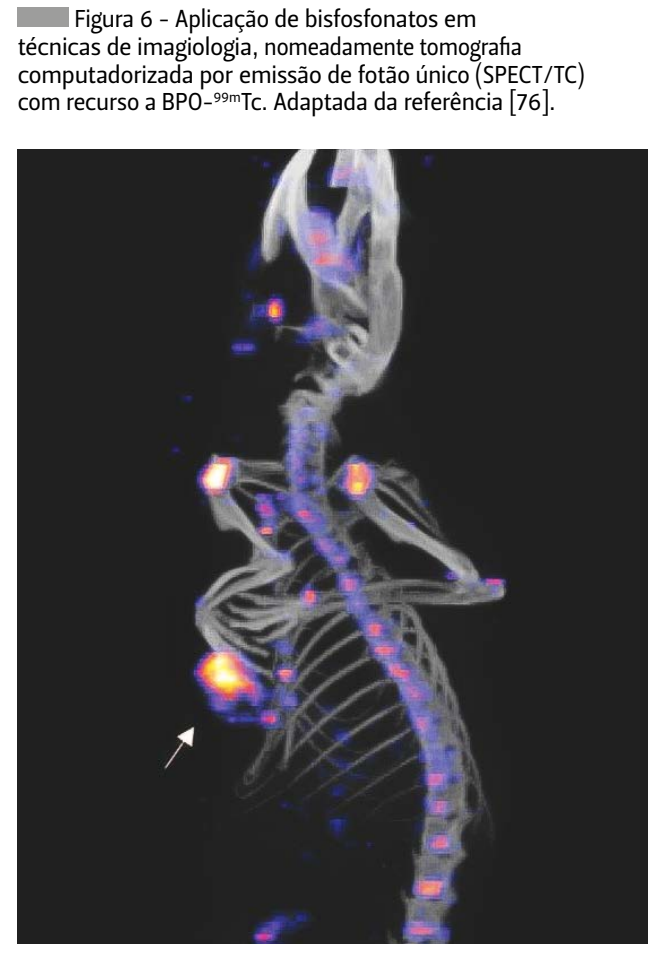

técnicas de imagiologia, nomeadamente tomogra

computadorizada por emissão de fotão único (SPECT/TC)

BPO-99mTc. Adaptada da referência [76]

\subsection{BPOs como agentes quelantes}

Tal como referido inicialmente, uma das características estruturais específicas dos BPOs é o seu grupo central P-C-P (Figuras 1 e 2). A importância deste grupo para a aplicação terapêutica dos BPOs é já conhecida. No entanto, novas aplicações podem ser encontradas. Tal é o caso de um estudo reportado por Wang et al., em 2006, no qual foram sintetizadas nanopartículas magnéticas e biocompatíveis revestidas por BPOs. Estas nanopartículas, através dos dois grupos fosfónicos presentes na estrutura dos BPOs, permitiram, por coordenação, remover iões de uranilo de amostras de água e de sangue, de forma eficiente e seletiva (Figura 7) [80]. Esta abordagem permitirá eliminar, de fluídos corporais, iões metálicos que, a determinadas dosagens, possam apresentar um risco toxicológico para os humanos.

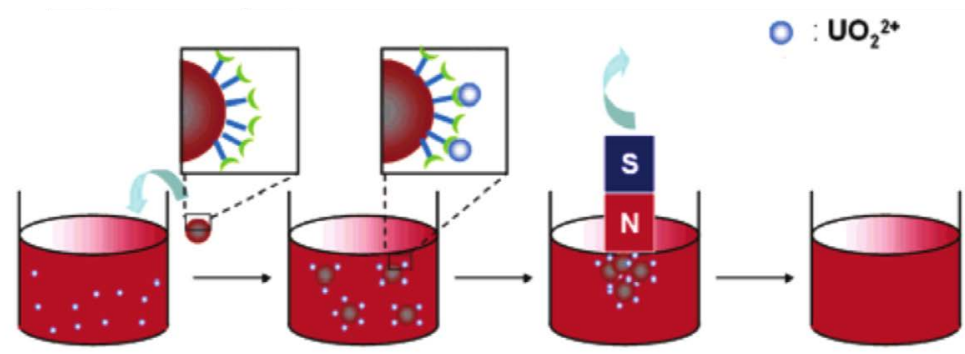

Figura 7 - llustração do uso de bisfosfonatos como revestimento de nanoparticulas magnéticas, para a remoção seletiva de iões uranilo do sangue. Adaptada da referência [80]. 
Num estudo recente, foi usado um novo derivado de BPO, o tetrabutil[(2,2'-bipiridino)-5,5'-diilbis(metileno) difosfonato] (Figura 8), para detetar a presença de iões de zinco $\left(Z n^{2+}\right)$ por um mecanismo de fluorescência. O BPO foi testado quer na forma livre, quer incorporado numa membrana, tendo-se mostrado que permite quantificar $\mathrm{Zn}^{2+}$ tanto em soluções aquosas de sais, como em soluções de fármacos (de origem e estrutura não discriminadas). 0 processo de deteção apresentou um tempo de resposta rápido (ca. 15 s), sendo também um processo seletivo e com boa sensibilidade para $\mathrm{Zn}^{2+}$ a outros iões $\left(\mathrm{Ca}^{2+}, \mathrm{Fe}^{2+}, \mathrm{Cr}^{3+}\right.$ ou $\mathrm{Mg}^{2+}$ ). Foi ainda estudado o potencial de aplicação deste BPO como marcador fluorescente de $\mathrm{Zn}^{2+}$ em microscopia de células, tendo-se verificado que marca eficazmente o $\mathrm{Zn}^{2+}$ intracelular em culturas celulares de células HeLa, e que não apresenta citotoxicidade nesta linha celular [81].

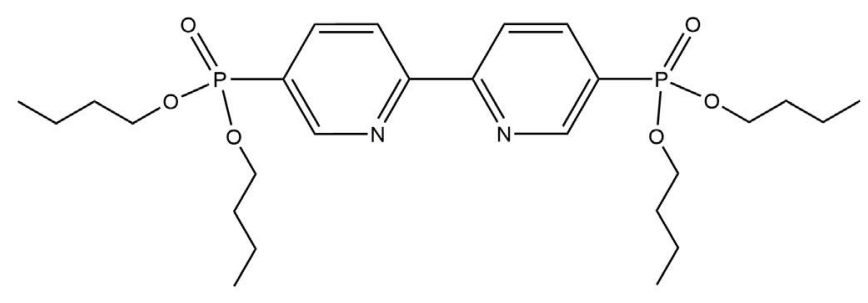

Figura 8 - Tetrabutil[(2,2'-bipiridino)5,5'-diilbis(metileno)difosfonato].

\section{5. "With great properties, comes great demand": O desafio na preparação de BPOs}

0 envelhecimento das populações nos países desenvolvidos tem levado a uma crescente procura por medicamentos à base de BPOs. Torna-se, por isso, necessário encontrar processos que permitam a sua fácil, rápida e eficiente preparação.

A síntese e preparação de BPOs tem sido alvo de vários estudos e patentes $[61,82,83]$. De entre as diferentes abordagens de síntese, aquela que mais se usa para a preparação em grande escala na indústria farmacêutica é a reação entre o ácido fosforoso ou fosfórico, o tricloreto de fósforo e um ácido carboxílico adequado ao BPO que se pretende obter; segue-se uma etapa de hidrólise (Esquema 1) [82-84]. Por vezes, em alternativa ao tricloreto de fósforo, é utilizado o oxicloreto de fósforo ou o pentacloreto de fósforo [85-87].

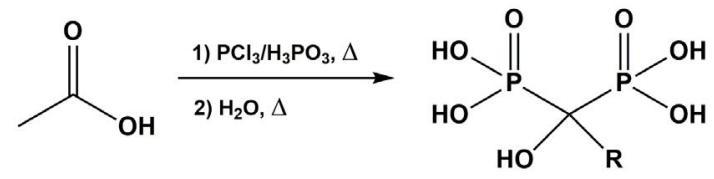

Esquema 1 - Esquema reacional da síntese de BPOs.
A reação é relativamente simples. Além de consistir em poucas etapas, não complexas, os reagentes e solventes utilizados são acessíveis. No final, o rendimento está dependente de dois fatores principais: (i) o solvente e (ii) as proporções de reagentes utilizados.

O solvente utilizado na reação influencia a homogeneidade da mistura reacional, podendo levar à formação de fases heterogéneas. Com efeito, e ao longo do tempo de reação, é usual observar-se um espessamento parcial e gradual da mistura, obtendo-se, no final, uma mistura extremamente viscosa. Como resultado, a capacidade de homogeneizar o meio reacional fica limitada, pelo que o ácido carboxílico pode não reagir completamente e a eficiência da reação fica comprometida [82,88-93]. Numa tentativa de minimizar este espessamento, foi testada uma grande variedade de solventes como meio reacional. Por exemplo, algumas patentes descrevem o uso de sulfolano como solvente para obter uma mistura reacional homogénea e fluida, permitindo sintetizar vários BPOs com bons rendimentos [92,94-96]. É também de destacar o uso do ácido metassulfónico (MSA) como solvente, que permite manter a mistura reacional fluida, possibilitando assim uma maior taxa de conversão do ácido carboxílico no respetivo BPO [82,94,95,97-101].

A quantidade correta de ácido fosforoso ou fosfórico e tricloreto de fósforo, também conhecidos como reagentes- $P$, é um outro fator determinante para a eficiência da reação. Está demonstrado que diferentes quantidades de reagentes-P resultam em diferentes rendimentos de reação [82]. Foi ainda demonstrado que para reações feitas com o solvente MSA, o rendimento aumenta com o aumento da proporção de tricloreto de fósforo/ ácido fosforoso (Tabela 3). De facto, quando este último é usado sem o primeiro não é possível sintetizar o BPO, permitindo assim postular que o ácido fosforoso seria desnecessário para a reação. No entanto, quando a síntese é realizada noutros solventes, esta hipótese nem sempre se verifica. Por exemplo, quando a síntese é feita em sulfolano, não é possível usar apenas ácido fosforoso para obter os BPOs. Por sua vez, usar apenas tricloreto de fósforo também não permite obter BPOs, ou então estes formam-se com rendimentos muito baixos. Uma possível explicação para estes resultados será que o solvente MSA tenha a capacidade de reagir com o tricloreto de fósforo e de desencadear a reação [102]. Deste modo, postula-se agora que solventes incapazes de reagir com o tricloreto de fósforo, como o sulfolano, necessitem de ambos os reagentes-P para que a reação ocorra de forma eficiente e com bom rendimento. 
Em pleno século XXI, numa era em que o conceito de sustentabilidade está cada vez mais presente nas nossas mentes, é expectável que também dentro dos grupos de investigação se almeje a incluir este conceito nos estudos a realizar [103]. Neste contexto, um dos métodos de maior interesse é a síntese assistida por micro-ondas [104-107]. Este é um processo simples e eficaz no qual ocorre o aquecimento uniforme e rápido dos vasos reacionais, reduzindo-se assim o tempo de reação e aumentando o rendimento. As reações usando micro-ondas são muito seletivas, permitindo obter produtos puros, o que se torna particularmente atraente para a indústria $[57,104,108]$.

A preparação de sais de alendronato, pamidronato, risedronato e zoledronato por este método, num processo de duas etapas (Esquema 2), foi reportada recentemente [109]. Comparativamente com processos convencionais de síntese, que envolvem procedimentos de aquecimento tradicionais, a síntese por em micro-ondas permitiu reduzir significativamente o tempo de reação de várias horas para ca. de 17 min. Este resultado é ainda mais notável tendo em conta que os rendimentos obtidos por ambos os procedimentos são semelhantes (Tabela 4).
Tabela 3 - Exemplos de condições reacionais usadas para sintetizar pamidronato e alendronato.

\begin{tabular}{|c|c|c|c|c|c|c|}
\hline & $\begin{array}{c}\text { Estequiometria } \\
\mathrm{RCOOH}: \mathrm{PCl}_{3}: \mathrm{H}_{3} \mathrm{PO}_{3}\end{array}$ & Solvente & $\begin{array}{l}\text { Tempo de } \\
\text { Reação } \\
(\mathrm{h})^{*}\end{array}$ & $\begin{array}{l}\text { Temp. } \\
\left({ }^{\circ} \mathrm{C}\right)^{* *}\end{array}$ & $\begin{array}{l}\text { Rendimento } \\
(\%)\end{array}$ & Ref. \\
\hline \multirow{10}{*}{ 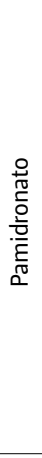 } & $1: 3,2: 0$ & MSA & $12-16$ & 75 & 57 & \multirow{10}{*}{ 용 } \\
\hline & $1: 2,2: 1,1$ & MSA & $12-16$ & 75 & 28 & \\
\hline & $1: 2,2: 2,2$ & MSA & $12-16$ & 75 & 27 & \\
\hline & $1: 1,1: 2,2$ & MSA & $12-16$ & 75 & 3 & \\
\hline & $1: 0: 3,2$ & MSA & $12-16$ & 75 & 0 & \\
\hline & $1: 3,2: 0$ & Sulfolano & $12-15$ & 75 & 0 & \\
\hline & $1: 2: 1$ & Sulfolano & $12-15$ & 75 & 42 & \\
\hline & $1: 2: 2$ & Sulfolano & $12-15$ & 75 & 63 & \\
\hline & $1: 1: 2$ & Sulfolano & $12-15$ & 75 & 44 & \\
\hline & $1: 0: 3,2$ & Sulfolano & $12-15$ & 75 & 0 & \\
\hline \multirow{6}{*}{$\begin{array}{l}\frac{0}{\pi} \\
\stackrel{0}{0} \\
\frac{0}{\overline{0}} \\
\frac{0}{0} \\
\frac{0}{4}\end{array}$} & 1:3:0 & Sulfolano & 6 & 75 & 8 & \multirow{6}{*}{ 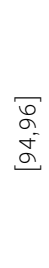 } \\
\hline & $1: 2: 1$ & Sulfolano & 6 & 75 & 37 & \\
\hline & $1: 3: 2$ & Sulfolano & 6 & 75 & 52 & \\
\hline & $1: 2: 2$ & Sulfolano & 6 & 75 & 46 & \\
\hline & $1: 2,5: 3,5$ & Sulfolano & $19-20$ & $60-65$ & 55 & \\
\hline & 1:0:3 & Sulfolano & 6 & 75 & 0 & \\
\hline
\end{tabular}

* Tempo de reação: compreende as etapas 1 e 2 do procedimento de síntese apresentado no Esquema 1. ** Temperatura à qual ocorre a etapa 1 do procedimento de síntese apresentado no Esquema 1. A etapa 2 (hidrólise) é um processo de refluxo, sendo que a temperatura varia tendo em conta o solvente usado.

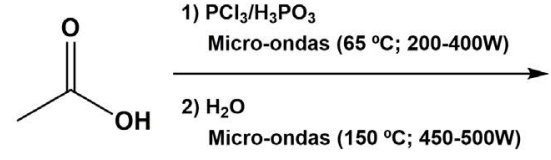<smiles>[R]C(O)(P(=O)(O)O)P(=O)(O)O</smiles>

Esquema 2 - Esquema reacional para a síntese de BPOs em microondas, partindo de uma mistura de um ácido carboxílico apropriado, ácido fosforoso e tricloreto de fósforo na proporção de 1:3:3, e usando sulfolano como solvente reacional.

Tabela 4 - Síntese assistida por micro-ondas versus síntese convencional de BPOs [109].

\begin{tabular}{|c|c|c|c|c|c|c|}
\hline & \multicolumn{3}{|c|}{ Síntese em Micro-ondas } & \multicolumn{2}{c|}{ Aquecimento Convencional } \\
\hline & \multicolumn{2}{|c|}{$\begin{array}{c}\text { Tempo de reação } \\
(\text { min) }\end{array}$} & \multirow{2}{*}{$\begin{array}{c}\text { Rendim. } \\
(\%)\end{array}$} & \multicolumn{2}{|c|}{$\begin{array}{r}\text { Tempo de reação } \\
(\text { min) }\end{array}$} & \multirow{2}{*}{$\begin{array}{c}\text { Rendim. } \\
(\%)\end{array}$} \\
\cline { 2 - 3 } & Passo 1 & Passo 2 & & Passo 1 & Passo 2 & \\
\hline Pamidronato & 3,15 & 10 & 64 & 210 & 360 & 72 \\
\hline Alendronato & 7 & 10 & 41 & 210 & 360 & 38 \\
\hline Risedronato & 3,15 & 10 & 74 & 210 & 360 & - \\
\hline Zoledronato & 3,45 & 10 & 70 & 210 & 360 & 67 \\
\hline
\end{tabular}

\section{Conclusões}

Os bisfosfonatos fazem parte do quotidiano de muitos pacientes, embora sejam frequentemente mais conhecidos pelos seus nomes comerciais do que pela sua classe química. De facto, existe no mercado uma vasta gama de formulações farmacêuticas e de marcas comerciais de fármacos contendo BPOs. Estes fármacos são prescritos para o tratamento de pacientes que apresentem patologias no tecido ósseo e no seu metabolismo, sendo o uso terapêutico mais frequente o tratamento e prevenção da osteoporose, mas podendo incluir-se outras patologias como a doença de Paget e lesões ósseas associadas a neoplasias.

A eficácia dos BPOs no aumento da densidade óssea em pacientes com osteoporose é bem conhecida, embora os valores sejam relativamente baixos, ca. $10 \%$. Mais ainda, as formulações orais disponíveis, além de 
causarem um forte impacto no aparelho digestivo, apresentam também valores de biodisponibilidade muito baixos. Estes factos levam a ponderar sobre o desenvolvimento de formulações mais eficazes ou que permitam, numa só toma, a administração de terapias combinadas. Para tal, podem preparar-se fórmulas contendo os BPOs e outros componentes vitais para o metabolismo ósseo, como por exemplo o cálcio. Para a redução dos efeitos secundários e aumento da biodisponibilidade, existem já algumas propostas inovadoras, com formulações desenhadas para a administração local no osso (na forma de scaffolds, cimentos ou géis injetáveis) e nos dentes.

Os BPOs estão também a ser alvo de estudos que visam alargar as suas aplicações clínicas, destacando-se o seu uso como agentes imagiológicos para o tecido ósseo. A potencialidade deste tipo de aplicação é fortemente sustentada pela elevada

\section{Notas}

1 - Apesar da sua aparência sólida e robusta, os ossos são tecidos dinâmicos que se encontram num contínuo processo de remodelação. Este processo é crucial para a reparação e renovação do tecido ósseo e é composto por duas etapas principais: (1) formação de tecido ósseo (por células denominadas osteoblastos) e (2) destruição de tecido ósseo (por células denominadas osteoclastos). especificidade dos BPOs para o osso. No entanto, a sua eventual aplicabilidade fica condicionada à segurança toxicológica dos radioisótopos que serão usados.

De modo a possibilitar todas estas aplicações, torna-se, portanto, imperativo melhorar os procedimentos pelos quais os BPOs são obtidos. Começando pelo processo de síntese, pode optar-se pelo uso da síntese em micro-ondas, que introduz uma maior sustentabilidade ao reduzir drasticamente o tempo de síntese e, logo, a energia necessária para a mesma. Adicionalmente, pode tentar-se otimizar a síntese de forma a usar solventes ou misturas de solventes que, mantendo a capacidade de homogeneizar a mistura reacional, sejam de manuseamento mais fácil, seguro e ecológico. Idealmente, a Ciência deverá encontrar um processo eficaz e sustentável para produzir BPOs em quantidade suficiente para responder às necessidades globais.

\section{Agradecimentos}

Este trabalho foi desenvolvido no âmbito do projeto QOPNA (Ref. FCT UID/QUI/00062/2019), LAQV-REQUIMTE (Ref. UIDB/50006/2020) e CICECO - Instituto de Materiais de Aveiro (Ref. UIDB/50011/2020 \& UIDP/50011/2020), financiado por fundos nacionais através da FCT/MEC e quando aplicável cofinanciado pelo FEDER, no âmbito do Acordo de Parceria PT2020. Agradecemos ainda à FCT pelo financiamento da bolsa de Doutoramento PD/BD/135104/2017 (para JSB).

\section{Referências}

[1] G. Petroianu, Pharmazie 2011, 66, 804-807. DOI: 10.1691/ph.2011.1053.

[2] R. G. G. Russell, Bone 2011, 49, 2-19. DOI: 10.1016/j.bone.2011.04.022.

[3] H. Fleisch, R. Russell, S. Bisaz, R. Mühlbauer, D. Williams, Eur. J. Clin. Invest. 1970, 1, 12-18. DOI: 10.1111/j.1365-2362.1970.tb00591.x.

[4] H. Fleisch, R. Graham, G. Russell, M.D. Francis, Science 1969, 165, 1262-1264. DOI: 10.1126/science.165.3899.1262.

[5] R. G. G. Russell, N. B. Watts, F.H. Ebetino, M. J. Rogers, Osteoporos. Int. 2008, 19 733-759. DOI: 10.1007/s00198-007-0540-8.

[6] D. Goltzman, Nat. Rev. Drug Discov. 2002, 1, 784-792. DOI: 10.1038/nrd916.

[7] R. G. G. Russell, M. J. Rogers, Bone 1999, 25, 97-106. DOI: 10.1016/s87563282(99)00116-7.

[8] S. D. Vasikaran, Ann. Clin. Biochem. 2001, 38, 608-623. DOI: 10.1258/0004563011901037.

[9] G. H. Nancollas, R. Tang, R. J. Phipps, Z. Henneman, S. Gulde, W. Wu, A. Mangood, R. G. G. Russell, F. H. Ebetino, Bone 2006, 38, 617-627. DOI: 10.1016/j.bone.2005.05.00.

[10] J. E. Dunford, K. Thompson, F. P. Coxon, S. P. Luckman, F. M. Hahn, C.D. Poulter, F. H. Ebetino, M. J. Rogers, J. Pharmacol. Exp. Ther. 2001, 296, 235242. jpet.aspetjournals.org/content/296/2/235.

[11] S. L. Teitelbaum, Science 2000, 289, 1504-1508. DOI: 10.1126/ science.289.5484.1504

[12] P. Clézardin, Bone 2011, 48, 71-79. DOI: 10.1016/j.bone.2010.07.016.

[13] A. J. Roelofs, K. Thompson, S. Gordon, M. J. Rogers, Clin. Cancer Res. 2006,
12, 6222s-6230s. DOI: 10.1158/1078-0432.CCR-06-0843.

[14] M. J. Rogers, J. C. Crockett, F. P. Coxon, J. Mönkkönen, Bone 2011, 49, 34-41. DOI: 10.1016/j.bone.2010.11.008.

[15] F. H. Ebetino, A.-M. L. Hogan, S. Sun, M. K. Tsoumpra, X. Duan, J. T. Triffitt, A.A. Kwaasi, J. E. Dunford, B. L. Barnett, U. Oppermann, Bone 2011, 49, 20-33. DOI: 10.1016/j.bone.2011.03.774.

[16] F. P. Coxon, K. Thompson, M. J. Rogers, Curr. Opin. Pharmacol. 2006, 6, 307-312. DOI: 10.1016/j.coph.2006.03.005.

[17] FDA U.S. Food and Drug Administration. Drugs@FDA: FDA Approved Drug Products. Disponível em: https://www.accessdata.fda.gov/scripts/cder/ daf/index.cfm (acedido em 26/11/2019).

[18] C. Holroyd, C. Cooper, E. Dennison, Best Pract. Res. Clin. Endocrinol. Metab. 2008, 22, 671-685. DOI: 10.1016/j.beem.2008.06.001.

[19] M. J. Seibel, Clin. Biochem. Rev. 2005, 26, 97-122. ncbi.nlm.nih.gov/pmc/ articles/PMC1320175.

[20] E. Hernlund, A. Svedbom, M. Ivergard, J. Compston, C. Cooper, J. Stenmark, E. V. McCloskey, B. Jonsson, J. A. Kanis, Arch. Osteoporos. 2013, 8, 1-115. DOI: 10.1007/s11657-013-0136-1.

[21] S. R. Cummings, J. L. Kelsey, M. C. Nevitt, K.J. O'DOWD, Epidemiol. Rev. 1985, 7, 178-208. DOI: 10.1093/oxfordjournals.epirev.a036281.

[22] B. L. Riggs, L. J. Melton, Bone 1995, 17, S505-S511. DOI: 10.1016/87563282(95)00258-4.

[23] Osteoporose afeta 500 mil portugueses, Expresso, Dossiê especial, Saúde Publica - dia Mundial da Osteoporose, 2012, pp. 1-8. 
[24] J. R. Berenson, A. Lichtenstein, L. Porter, M. A. Dimopoulos, R. Bordoni , S. George, A. Lipton, A. Keller, O. Ballester, M.J. Kovacs, H.A. Blacklock, R. Bell, J. Simeone, D.J. Reitsma, M. Heffernan, J. Seaman, R.D. Knight, N. Engl. J. Med. 1996, 334, 488-493. DOI: 10.1056/NEJM199602223340802.

[25] N. B. Watts, D. L. Diab, J. Clin. Endocrinol. Metab. 2010, 95, 1555-1565. DOI: 10.1210/jc.2009-1947.

[26] D. Hosking, K. Lyles, J. P. Brown, W. D. Fraser, P. Miller, M. D. Curiel, J. P. Devogelaer, M. Hooper, G. Su, K. Zelenakas, J. Bone Miner. Res. 2007, 22 142-148. DOI: 10.1359/jbmr.061001.

[27] D. K. Wysowski, P. Greene, Bone 2013, 57, 423-428. DOI: 10.1016/j.bone.2013.09.008.

[28] G. A. Rodan, T. J. Martin, Science 2000, 289, 1508-1514. DOI: $10.1126 /$ science.289.5484.1508

[29] INFARMED - Autoridade Nacional do Medicamento e Produtos de Saúde, I.P. Disponível em: http://app7.infarmed.pt/infomed/pesquisa.php (acedido em 26/11/2019)

[30] H. G. Bone, D. Hosking, J.-P. Devogelaer, J. R. Tucci, R. D. Emkey, R. P. Tonino, J. A. Rodriguez-Portales, R. W. Downs, J. Gupta, A. C. Santora, U. A. Liberman N. Engl. J. Med. 2004, 350, 1189-1199. DOI: 10.1056/NEJMoa030897.

[31] P. Ravn, B. Clemmesen, B. J. Riis, C. C, Bone 1996, 19, 527-533. DOI: 10.1016/S8756-3282(96)00229-3.

[32] J.-Y. Reginster, H. Minne, O. Sorensen, M. Hooper, C. Roux, M. Brandi, B. Lund, D. Ethgen, S. Pack, I. Roumagnac, Osteoporos. Int. 2000, 11, 83-91. DOI: 10.1007/s001980050010.

[33] D. M. Black, P. D. Delmas, R. Eastell, I. R. Reid, S. Boonen, J. A. Cauley, F. Cosman, P. Lakatos, P. C. Leung, Z. Man, C. Mautalen, P. Mesenbrink, H. Hu, J. Caminis, K. Tong, T. Rosario-Jansen, J. Krasnow, T.F. Hue, D. Sellmeyer, E. F. Eriksen, S. R. Cummings N. Engl. J. Med. 2007, 356, 1809 1822. DOI: 10.1056/NEJMoa067312.

[34] FDA U.S. Food and Drug Administration. USP Therapeutic Categories Model Guidelines. Disponível em: https://www.accessdata.fda.gov/scripts/cder/ daf/index.cfm (acedido em 10/12/2019).

[35] N. B. Watts, Rheum. Dis. Clin. North Am. 2001, 27, 197-214. DOl: 10.1016/s0889-857x(05)70194-0.

[36] M. M. Iqbal, South. Med. J. 2000, 93, 2-18. DOI: 10.1097/00007611-200093010-00002.

[37] J. R. Berenson, B. E. Hillner, R. A. Kyle, K. Anderson, A. Lipton, G. C. Yee, J. S. Biermann, J. Clin. Oncol. 2002, 20, 3719-3736. DOl: 10.1200/ JCO.2002.06.037.

[38] B. E. Hillner, J. N. Ingle, J. R. Berenson, N. A. Janjan, K. S. Albain, A. Lipton, G. Yee, J. S. Biermann, R. T. Chlebowski, D. G. Pfister, J. Clin. Oncol. 2000 18, 1378-1391. DOI: 10.1200/JCO.2000.18.6.1378.

[39] G. Hechmati, S. Cure, A. Gouepo, H. Hoefeler, V. Lorusso, D. Lüftner, I. Duran, C. Garzon-Rodriguez, J. Ashcroft, R. Wei, J. Med. Econ. 2013, 16, 691-700. DOl: 10.3111/13696998.2013.779921.

[40] European Medicines Agency: Science, Medicines, Health. Questions and answers on the review of bisphosphonates and atypical stress fractures. 2011 (EMA/288359/2011 Rev.1).

[41] E. V. Giger, B. Castagner, J.-C. Leroux, J. Control. Release 2013, 167, 175-188 DOI: 10.1016/j.jconrel.2013.01.032.

[42] A. Kuźnik, A. Październiok-Holewa, P. Jewula, N. Kuźnik, Eur. J. Pharmacol. 2020, 866, 172773. DOI: 10.1016/j.ejphar.2019.172773.

[43] K. B. Farrell, A. Karpeisky, D.H. Thamm, S. Zinnen, Bone Rep. 2018, 9, 4760. DOI: 10.1016/j.bonr.2018.06.007.

[44] N. Pfannkuchen, M. Meckel, R. Bergmann, M. Bachmann, C. Bal, M. Sathekge, W. Mohnike, R. P. Baum, F. Rösch, Pharmaceuticals (Basel) 2017 10, 45. DOI: 10.3390/ph10020045.

[45] K. A. Kennel, M. T. Drake, Mayo Clin. Proc. 2009, 84, 632-637. DOI: 10.1016/S0025-6196(11)60752-0.

[46] P. C. De Groen, D. F. Lubbe, L. J. Hirsch, A. Daifotis, W. Stephenson, D. Freedholm, S. Pryor-Tillotson, M. J. Seleznick, H. Pinkas, K. K. Wang, N. Engl. J. Med. 1996, 335, 1016-1021. DOI: 10.1056/NEJM199610033351403.

[47] J. Green, G. Czanner, G. Reeves, J. Watson, L. Wise, V. Beral, Br. Med. J. 2010, 341, c4444. DOI: 10.1136/bmj.c4444.

[48] R. E. Marx, J. Oral Maxillofac. Surg. 2003, 61, 1115-1117. DOI: 10.1016/s0278-2391(03)00720-1.

[49] S. Khosla, D. Burr, J. Cauley, D. W. Dempster, P. R. Ebeling, D. Felsenberg, R. F. Gagel, V. Gilsanz, T. Guise, S. Koka, J. Bone Miner. Res. 2007, 22, 1479-1491. DOI: 10.1359/jbmr.0707onj.

[50] M. A. Perazella, G. S. Markowitz, Kidney Int. 2008, 74, 1385-1393. DOI: 10.1038/ki.2008.356.

[51] J. H. Lin, Bone 1996, 18, 75-85. DOI: 10.1016/8756-3282(95)00445-9.
[52] S. Cremers, S. Papapoulos, Bone 2011, 49, 42-49. DOI: 10.1016/j.bone.2011.01.014.

[53] L. Hyldstrup, G. Flesch, S. Hauffe, Calcif. Tissue Int. 1993, 53, 297-300. DOI: 10.1007/BF01351831.

[54] FDA Database of Approved Drug Products. FOSAMAX(R) (Alendronate sodium). Available at: https://www.accessdata.fda.gov/scripts/cder/daf/ index.cfm?event $=$ overview. process $\& A p p \mid N o=020560$ [Acedido em 05/01/2018]

[55] FDA Database of Approved Drug Products. BONIVA(R) (Ibandronate sodium). Available at: www.accessdata.fda.gov/scripts/cder/daf/ /index.cfm?event $=$ overview.process\&App|No=021455 [Acedido em 05/01/2018]

[56] B. Leyland-Jones, Eur. J. Cancer Sup. 2004, 2, 9-12. DOI: 10.1016/j.ejcsup.2004.01.003.

[57] C.O. Kappe, D. Dallinger, Nat. Rev. Drug Discov. 2006, 5, 51-63. DOI: $10.1038 / \mathrm{nrd} 1926$

[58] D. Y. Mitchell, W. H. Barr, R. A. Eusebio, K. A. P. Stevens, F. P. Duke, D. A. Russell, J. D. Nesbitt, J. H. Powell, G. A. Thompson, Pharm. Res. 2001, 18, 166-170. DOI: 10.1023/A:1011024200280.

[59] FDA Database of Approved Drug Products. AREDIA(R) (Pamidronate disodium). Available at: https://www.accessdata.fda.gov/scripts/cder/daf/ index.cfm?event $=$ overview.process\&ApplNo=020927. [Acedido em 05/01/2018].

[60] FDA Database of Approved Drug Products. ZOMETA(R) (Zoledronic acid). Available at: https://www.accessdata.fda.gov/scripts/cder/daf/ index.cfm? event $=0$ verview. process\&ApplNo=021223. [Acedido em 05/01/2018].

[61] M. Lecouvey, Y. Leroux, Heteroat. Chem. 2000, 11, 556-561. DOI: 10.1002/1098-1071(2000)11:7<556::AID-HC15>3.0.CO;2-N

[62] E. M. Lewiecki, Core Evid. 2009, 4, 13-23. DOI: 10.2147/ce.s6011.

[63] F. B. Torstrick, R. E. Guldberg, Curr. Osteoporos. Rep. 2014, 12, 33-40. DOI: 10.1007/s11914-014-0191-6.

[64] Ł. Matuszewski, K. Turżańska, A. Matuszewska, M. Jabłoński, I. Polkowska, T. Mazurkiewicz, Int. Orthop. 2013, 37, 1187-1193. DOI: 10.1007/s00264-013-1855-z.

[65] E. Verron, M.-L. Pissonnier, J. Lesoeur, V. Schnitzler, B. H. Fellah, H. PascalMoussellard, P. Pilet, O. Gauthier, J.-M. Bouler, Acta Biomater. 2014 10, 4887-4895. DOI: 10.1016/j.actbio.2014.07.012.

[66] K. Farbod, K. Sariibrahimoglu, A. Curci, A. Hayrapetyan, J.N. Hakvoort, J.J. van den Beucken, M. lafisco, N. Margiotta, S.C. Leeuwenburgh, Tissue Eng. Part A 2016, 22, 788-800. DOI: 10.1089/ten.TEA.2016.0001.

[67] G. T. Reddy, T. P. Kumar, K. Veena, Drug Deliv. 2005, 12, 217-222. DOI: 10.1080/10717540590952663.

[68] A. Bigi, E. Boanini, J. Funct. Biomater. 2018, 9, 6 . DOI: $10.3390 / \mathrm{jfb} 9010006$

[69] M. Fazil, S. Baboota, J. K. Sahni, Ameeduzzafar, J. Ali, Drug Deliv. 2015, 22, 1-9. DOI: 10.3109/10717544.2013.870259.

[70] K. M. Hosny, O. A. Ahmed, R. T. Al-Abdali, Expert Opin. Drug Deliv. 2013, 10, 741-746. DOI: 10.1517/17425247.2013.799136.

[71] D. T. Breul, S. Silva-Lejmi, S. R. Savu, L. Silvestro, Pilot Bioavailability Study of a novel Bisphosphonate Osteotropic Drug Delivery System by Oral Route, for Metastatic Bone Treatment. Disponível em: inscb.org/uploads/ pilot\%20bioavailability\%20study.pdf, 2011

[72] L. E. Cole, T. Vargo-Gogola, R. K. Roeder, Adv. Drug Deliv. Rev. 2016, 99, 12-27. DOI: 10.1016/j.addr.2015.10.005.

[73] H. Uludag, Curr. Pharm. Des. 2002, 8, 1929-44. DOI: 10.2174/1381612023393585

[74] H. Hirabayashi, T. Takahashi, J. Fujisaki, T. Masunaga, S. Sato, J. Hiroi, Y. Tokunaga, S. Kimura, T. Hata, J. Control. Release 2001, 70, 183-191. DOI: 10.1016/s0168-3659(00)00355-2.

[75] S. Rudnick-Glick, E. Corem-Salkmon, I. Grinberg, E. Gluz, S. Margel, SPIE 2015, 9550, 955004. DOI: 10.1117/12.2186765.

[76] K. R. Bhushan, P. Misra, F. Liu, S. Mathur, R. E. Lenkinski, J. V. Frangioni, J. Am Chem. Soc. 2008, 130, 17648-17649. DOI: 10.1021/ja807099s.

[77] M. Fellner, R. P. Baum, V. Kubíček, P. Hermann, I. Lukeš, V. Prasad, F. Rösch, Eur. J. Nucl. Med. Mol. Imaging 2010, 37, 834-834. DOI: $10.1007 /$ s00259-009-1355-y.

[78] Z. Zha, Z. Wu, S. R. Choi, K. Ploessl, M. Smith, D. Alexoff, L. Zhu, H. F. Kung, Mol. Pharm. 2020, 17, 1674-1684. DOI: 10.1021/acs.molpharmaceut.0c00103

[79] S. Sun, K. M. Błażewska, A. P. Kadina, B. A. Kashemirov, X. Duan, J.T. Triffitt, J. E. Dunford, R. G. Russell, F. H. Ebetino, A. J. Roelofs, F. P. Coxon, M. W. Lundy, C. E. McKenna, Bioconjug. Chem. 2016, 27, 329-340. DOI: 10.1021/acs.bioconjchem.5b00369. 
[80] L. Wang, Z. Yang, J. Gao, K. Xu, H. Gu, B. Zhang, X. Zhang, B. Xu, J. Am. Chem. Soc. 2006, 128, 13358-13359. DOI: 10.1021/ja0651355.

[81] R. S. Kumar, S. K. A. Kumar, K. Vijayakrishna, A. Sivaramakrishna, P. Paira, C. V. S. B. Rao, N. Sivaraman, S. K. Sahoo, New J. Chem. 2018, 42, 8494-8502. DOI: 10.1039/C8NJ00158H.

[82] G. R. Kieczykowski, R. B. Jobson, D. G. Melillo, D. F. Reinhold, V. J. Grenda, I. Shinkai, J. Org. Chem. 1995, 60, 8310-8312. DOl: 10.1021/jo00130a036.

[83] L. Widler, K. A. Jaeggi, M. Glatt, K. Müller, R. Bachmann, M. Bisping, A.-R. Born, R. Cortesi, G. Guiglia, H. Jeker, J. Med. Chem. 2002, 45, 3721-3738. DOI: 10.1021/jm020819i.

[84] R. Balasubramaniam, P. Polsani, G. Tammireddy, Improved Process for the Preparation of Risendronate Sodium Hemipentahydrate. W02009/34580, 2009

[85] P. B. Deshpande, P. K. Luthra, Process for the preparation of biphosphonic derivatives U.S. Patent No 7,439,385, 2008.

[86] U. P. Senthilkumar, T. Arulmoli, V. S. Lakshmipathi, S. M. Rao, An improved process for the preparation of bisphosphonic acid. W02008/035131 A1, 2006

[87] R. Lidor-Hadas, Z. Harel, R. Lifshitz-Liron, E. Kovalevski-Ishai, Novel process for making bisphosphonic acids using diluents other than halogenated hydrocarbons. U.S. Patent No 11/350,462, 2006

[88] K. Dabak, A. E. Ozarslan, F. Sahbaz, T. Aslan, Process for the preparation of 4-amino-1-hydroxybutylidene-1, 1-biphosphonic acid. U.S. Patent No 7,009,071, 2006

[89] L. Dembkowski, R. Rynkiewicz, J. Rachoń, S. Makowiec, W. Przychodzeń, D. Witt, Process for the preparation of [1-hydroxy-2-(3-pyridinyl) ethylidene] bisphosphonic acid and hemipentahydrate monosodium salt thereof. U.S. Patent № 8,450,488, 2013.

[90] M. Szulc, T. Slisewski, L. Dembkowski, B. Jastrzebska, J. Rachon, S. Makowiec, A process for the synthesis of 1-hydroxy-3-(n-methylpentylamino) propylidene bisphosphonic acid monosodium salt, monohydrate. WO2011/016738 A1, 2011

[91] H. Blum, K. H. Worms, Process for the production of $\Omega$-amino-1hydroxyalkylidene-1, 1-bisphosphonic acid. U.S. Patent No 4,407,761, 1983

[92] V. M. Patel, T. R. Chitturi, R. Thennati, Process for preparation of bisphosphonic acid compounds. U.S. Patent No 7,411,087, 2008.

[93] M. Wieczorek, T. Stawinski, K. Chrulski, A process for the preparation of risedronic acid. European Patent EP1243592, 2002.

[94] D. I. Nagy, A. Grün, S. Garadnay, I. Greiner, G. Keglevich, Heteroat. Chem. 2017, 28, e21370. DOI: 10.1002/hc.21370.
[95] R. Kovács, A. Grün, 0. Németh, S. Garadnay, I. Greiner, G. Keglevich, Heteroat Chem. 2014, 25, 186-193. DOI: 10.1002/hc.21155.

[96] G. P. Singh, H. S. Jadhav, N. V. Maddireddy, D. Srivastava, Process for the production of 4-amino-1-hydroxybutylidene-1,1-bisphosphonic acid or salts thereof. W02007/010556 A1, 2007.

[97] G. R. Kieczykowski, Process for preparing 4-amino-1-hydroxybutylidene-1, 1-bisphosphonic acid (ABP) or salts thereof. U.S. Patent No 5,019,651, 1991

[98] G. Keglevich, A. Grün, K. Aradi, S. Garadnay, I. Greiner, Tetrahedron Lett. 2011 52, 2744-2746. DOI: 10.1016/j.tetlet.2011.03.093.

[99] G. Keglevich, A. Grün, S. Garadnay, I. Greiner, Phosphorus Sulfur Silicon Relat. Elem. 2015, 190, 2116-2124. DOI: 10.1080/10426507.2015.1072194.

[100] R. Kovács, A. Grün, S. Garadnay, I. Greiner, G. Keglevich, Green Process. Synth. 2014, 3, 111-116. DOI: 10.1515/gps-2013-0107.

[101] G. R. Kieczykowski, D. G. Melillo, R. B.Jobson, G. S. Brenner, Crystalline 4-amino-1-hydroxybutylidene-1, 1-bisphosphonic acid monosodium trihydrate, process therefor and compositions and use thereof. European Patent EP0402152 B1, 1995

[102] D. I. Nagy, A. Grün, S. Garadnay, I. Greiner, G. Keglevich, Molecules 2016, 21 , 1046. DOI: $10.3390 /$ molecules 21081046

[103] SusChem - European Technology Platform for Sustainable Chemistry, Available at: http://www.suschem.org/ [Acedido em 11/11/2017].

[104] M. Colombo, I. Peretto, Drug Discov. Today 2008, 13, 677-684. DOI: 10.1016/j.drudis.2008.03.007.

[105] S. M. Vilela, A. D. Firmino, R. F. Mendes, J. A. Fernandes, D. Ananias, A. A. Valente, H. Ott, L. D. Carlos, J. Rocha, J. P. Tomé, Chem. Commun. 2013, 49 6400-6402. DOI: 10.1039/C3CC42632G.

[106] M. Larhed, A. Hallberg, Drug Discov. Today 2001, 6, 406-416. DOI: 10.1016/S1359-6446(01)01735-4.

[107] S. H. Jhung, J. H. Lee, J. W. Yoon, C. Serre, G. Férey, J. S. Chang, Adv. Mater. 2007, 19, 121-124. DOI: 10.1002/adma.200601604.

[108] F. A. Bassyouni, S. M. Abu-Bakr, M. A. Rehim, Res. Chem. Intermed. 2012, 38, 283-322. DOI: 10.1007/s11164-011-0348-1.

[109] D. A. Mustafa, B. A. Kashemirov, C. E. McKenna, Tetrahedron Lett. 2011, 52, 2285-2287. DOI: 10.1016/j.tetlet.2011.02.058.

\section{Filipe A. Almeida Paz}

Licenciou-se pela Universidade de Aveiro (UA, 2000) e e obteve o doutoramento pela Universidade de Cambridge (Peterhouse College, Reino Unido) em Metal-Organic Frameworks (MOFs) e materiais zeolíticos. Regressou a Portugal em 2004 para criar o seu grupo de investigação em MOFs e na utilização de raios-X. É atualmente Investigador Principal da UA, onde também leciona nos três ciclos de estudos e membro do CICECO (Instituto de Materiais de Aveiro). É detentor de vários prémios, desta- cando-se a Medalha Vicente de Seabra (2015) da SPQ. Fundou o Grupo de Cristalografia da SPQ, e preside à Divisão de Química Inorgânica e Bioinorgânica. filipe.paz@ua.pt ORCID.org/0000-0003-2051-5645

\section{*Jéssica S. Barbosa}

É uma jovem Bioquímica que se encontra a frequentar o terceiro ano do Programa Doutoral em Química
Sustentável, na Universidade de Aveiro, desenvolvendo novos Metal-Organic Frameworks (MOFs) para futuras aplicações no tratamento da osteoporose. Este trabalho tem vindo a atrair grande interesse, tendo já conquistado, por dois anos consecutivos, o prémio de melhor aluna na área da Química Sustentável. É membro do CICECO (Instituto de Materiais de Aveiro) e LAQV-Requimte.

jessicambarbosa@ua.pt

ORCID.org/0000-0002-7220-661X

\section{Susana S. Braga}

É natural do Porto e fez a sua licenciatura nesta cidade, na Faculdade de Farmácia da Universidade do Porto. Continuou o seu percurso académico na Universidade de Aveiro, onde se doutorou em Química em 2003 e onde, desde então, tem vindo a desenvolver o seu trabalho de investigação. Publicou 67 artigos, 7 capítulos em livros e mais de 80 comunicações em conferências. É membro do LAQV-REQUIMTE.

sbraga@ua.pt ORCID.org/0000-0003-4460-970X 